\title{
Successful pregnancy outcomes following use of enoxaparin in recurrent pregnancy loss without apl antibodies-report of 2 cases
}

\begin{abstract}
Recurrent Pregnancy losses are defined as pregnancy losses up to 20 weeks of gestation age. Most causes are thrombophilias of which positive Antiphospholipid antibodies are the commoners, others being hereditary thrombophilias, uterine defects, infections, endocrine disorders like DM, thyroid disorders, hyperprolactinemia etc. Usually the treatment that is offered is empirical like progesterone, dydrogesterone, IV immune globulins, and intralipids and in thrombophilias due to positive APL antibodies Enoxaparin and low dose aspirins recommended but not as a routine. Here we report 2 cases of RPL where there was no APL anybody positivity but early Enoxaparin was started till 33 weeks and we got a positive result in the form of live fetus born at 37 plus weeks in both cases.
\end{abstract}

Volume I Issue 3 - 2017

\author{
Kulvinder Kochar Kaur,' Gautam Allahbadia, ${ }^{2}$ \\ Mandeep Singh ${ }^{3}$ \\ 'Kulvinder Kaur Centre For Human Reproduction, India \\ ${ }^{2}$ Rotunda-A Centre for Human reproduction, India \\ ${ }^{3}$ Consultant Neurologist, Swami Satyanand Hospital, India
}

Correspondence: Kulvinder Kochar Kaur, Kulvinder Kaur Centre for Human Reproduction, 72I, GTB Nagar, Jalandhar- |4400 I, India, Tel 91- |8|-46|3422, Fax 9|- |8|46|3422, Email kulvinder.dr@gmail.com

Received: September 15, 2017 | Published: November 24 2017

\section{Introduction}

Recurrent pregnancy loss (RPL) is defined as 3 consecutive abortions before 20 weeks. Causes can be varied from those involving positive antiphospholipid antibodies i.e. thrombophiliasie hereditary or non hereditary, or others like anatomic defects, endocrine causes, infections. Usually treatment is not definite but remains empirical but suggested treatment indicated remains progesterone, dydrogesterone, and Enoxaparin for those having positive antiphospholipid antibodies, iv immunoglobulin's for occasional cases. Usually low molecular weight heparin (Enoxaparin) is reserved for those who have a positive anticardiolipin antibody (ACL). ${ }^{1,2}$ Here we report 2 cases of RPL who did not have positive APL but responded successfully to Enoxaparin and pregnancies proceeded to term and resulted in live birth.

\section{Case I}

A 26 year old patient presented with history of secondary infertility- 6 Years with history of 3 previous spontaneous abortions at 6-8 weeks gestation age. Cycles were regular $3 / 30$, with average flow. Patient gave history of prior tubercular pneumothorax for which she required 9 months of ATT and tapping of chest. APL profile was negative. There was no history of thyroid dysfunction or DM. On Examination she weighed 46kg, height $165 \mathrm{~kg}$, BMI-17. $55 \mathrm{KG} /$ $\mathrm{m}^{2}$, normal BP of $110 / 70 \mathrm{~mm} \mathrm{Hg} .{ }^{3,4} \mathrm{Hb}$, TLC, DLC, and ESR were within normal limits. APL profile including anticardiolipin antibody, Antiphosphatidyl choline, RVVT, Apttk, anti nuclear antibody were negative. She conceived spontaneously and low molecular weight heparin (Enoxaparin) was started and continued till 33 weeks gestation age, when it was omitted for fear of PPH. She went into spontaneous labor at 38 weeks gestation age and delivered a live female baby weighing $2.8 \mathrm{~kg}$ with good apgar score 8,10 and baby was normal in neonatal period (Figure 1)

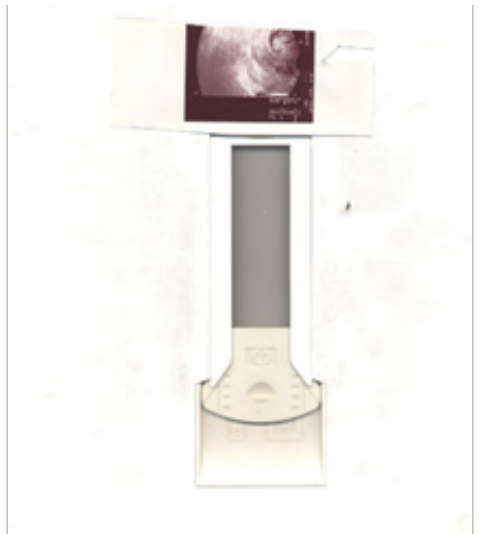

Figure I Patient gave history of prior tubercular pneumothorax for which she required 9 months of ATTT and tapping of chest.

\section{Case 2}

A 30 years old patient presented with secondary infertility 3 Years with history of previous 3 consecutive abortions around 14-15 weeks gestation age. Ultrasonography had revealed a normal intrauterine fetus with viability before the mishap. Cycles were regular 4/30 (Figure 2) (Figure 3). There was no history of thyroid dysfunction DM. On examination she weighed $67 \mathrm{~kg}$, height $163 \mathrm{~cm}$, BMI- 25 . $28 \mathrm{Kg} / \mathrm{m}^{2}$, BP was normal $120 / 80 \mathrm{mmhg}$. Investigations revealed normal HB, TLC, ESR, TFT, S. Prolactin, GTT, APL profile was negative including ACL, APL, RVVT, APTTK, ANA. She conceived by intrauterine insemination and had Enoxaparin started 40units/day and continued till 33 weeks gestation age. At 38 Weeks gestation due to large for date fetus, although she had normal GTT, an elective LSCS was done and she delivered a live male baby weighing $4 \mathrm{~kg}$ with normal apgar score 8,10 with fetus remaining normal neonatal. ${ }^{5}$ 


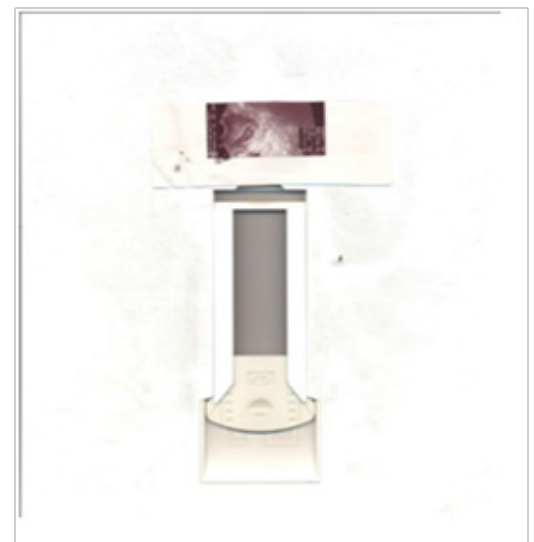

Figure 2 Single Viable Fetuses with CRL Corresponding to 7-8 weeks Ga.

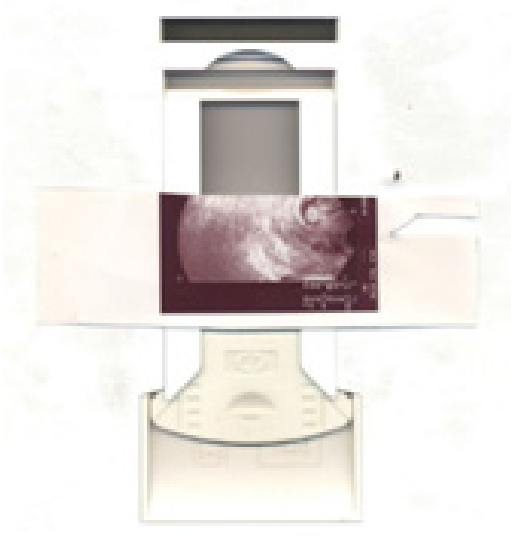

Figure 3 Single Viable Fetuses with CRL Corresponding to 7-8 weeks Ga.

\section{Conclusion}

Although it has been generalized that Enoxaparin should not be used as the first line of treatment for all case of RPL without APL it can be individualized for some cases where it may be of use in getting a live term delivery despite the contrary opinion as seen in these 2 cases. Similar examples get exemplified by reference number.

\section{Acknowledgements}

None.

\section{Conflict of interest}

The author declares no conflict of interest.

\section{References}

1. Kochar Kaur Kulvinder, Allahbadia GN, Singh M. An overview of therapeutic management of recurrent pregnancy loss. Open Access journal of Gynecology. 2017;2(3):1-14.

2. Jeve YB, Davies W. Evidence based management of recurrent miscarriages. J Hum Repr Sci. 2014;7(3):159-169.

3. Cling C, Magez J, Hedderich J, et al. Two year outcome after recurrent first trimester miscarriages: prognostic value of the past obstetric history. Arch Gynecol Obstet. 2016;293:1113-1133.

4. Leon Speroff, Fritz MA. In Clinical Gynecological Endocrinology and Infertility. 7th edition. Chapter 28-Recurrent early pregnancy loss-The evaluation and management of recurrent spontaneous losses in early pregnancy, India; 2007. p. 1069-1101.

5. Bundhun PK, Soogund MZ, Huang F. Impact of systemic lupus erythematosus on maternal and fetal outcomes following pregnancy: A meta-analysis of studies published between years 2001-2016. $J$ Autoimmun. 2017;79:17-27. 